\title{
Learning to think by learning LOGO: Rule learning in third-grade computer programmers
}

\author{
HENRY GORMAN, JR. \\ Austin College, Sherman, Texas \\ and \\ LYLE E. BOURNE, JR. \\ University of Colorado, Boulder, Colorado
}

\begin{abstract}
Gains in logical thinking are assumed to result from learning computer programming. Although such assumptions are commonly held, there is little empirical work on cognitive changes resulting from computer programming. The present study reports results of 15 third-grade students at a private school in Dallas who learned LOGO during the school year. One-third of the students were given $1 \mathrm{~h} /$ week of individual computer time (separate from in-class instruction), and the remaining students received $.5 \mathrm{~h} /$ week of individual computer time. At the end of the school year, the 1-h group did significantly better than the .5-h group on a conditional rulelearning task. Future research should compare gains from structured languages like LOGO with those of unstructured languages and should use additional assessment techniques.
\end{abstract}

A gain in logical thinking is imputed as a positive side effect of learning a procedural computer language such as LOGO (Papert, 1980). Although such gains are assumed almost as a cultural truism, there is a paucity of research either supporting or infirming that hypothesis. The lack of empirical testing of cognitive gains following computer training is understandable and results from several causes. First, so many of the pioneers in LOGO claim to have seen such dramatic changes in students in case-study work (e.g., Lawler, 1981; Weir, Note 1) that they regard formal testing as unnecessary (Papert, 1980). Second, until very recently, LOGO was available only on relatively expensive minicomputers, which effectively prohibited research on more than one or two children for more than just a few hours of computer work. Even a severe skeptic of putative cognitive gains from learning to program would not view the failure to discover a significant change in thinking after 3 or $4 \mathrm{~h}$ of programming training as a disconfirmation. Third, in the one study that had several children and that lasted a full school year (Watt, Papert, diSessa, \& Weir, Note 2), the researchers were ethically constrained from running a true experimental design, and so they used nonequivalent controls. Although these researchers reported gains in angle estimation, line magnitude estimation, and mirror-drawing in students after the students had been exposed to LOGO, they did not specifically test students on problem-solving tasks.

The first author's mailing address is: Department of Psychology, Austin College, Sherman, Texas 75090. The second author's mailing address is: Department of Psychology, University of Colorado, Boulder, Colorado 80302.
In an earlier study of effects of short exposures to LOGO, Statz (1973) found that fourth-grade students were able to understand the concept of recursion better after they had had some LOGO programming. However, she was unable to find any other gains, perhaps because the students did not have enough experience with LOGO or because most of her measures were success-failure, which are not particularly sensitive to measuring the active process of thinking.

The problem of measuring changes in thinking represents a serious obstacle to documenting such changes produced by learning to program. The case studies and the Statz (1973) and Watt et al. (Note 2) studies are encouraging, but are subject to numerous plausible alternative explanations. The present study was originally designed as a nonequivalent control quasi-experiment to document rule-learning gains after a year of LOGO programming; the study became a true double-blind random experiment when one-third of the students were fortuitously given twice as much LOGO training as the other students in the study.

The rationale for choosing a rule-learning task was fourfold. First, Bourne (1970) showed that there is a style of thinking that one learns from solving any of the four binary rules (conjunctive, disjunctive, conditional, and biconditional), that this cognitive style transfers positively to learning all of the other rules, and that this style involves a process of categorization like that of sorting by truth tables. Such a mode of thinking was recently attributed to computer programming (Kolata, 1982). Second, the Texas Instruments implementation of LOGO on the TI 99/4 microcomputer is especially rich in exemplars of independent attributes 
(e.g., sprite number, sprite color, sprite shape, sprite heading, sprite speed, sprite $\mathrm{x}$ - and $\mathrm{y}$-coordinates, and turtle states). Third, rule-learning tasks can be scored by the more sensitive measures of number of errors to criterion and number of trials to criterion, rather than by just success-failure. Finally, Bourne and O'Banion (1971) found a developmental trend in difficulty of problem solution such that the conjunctive rule was easiest and the biconditional most difficult. The conditional rule was selected for the present study because it is moderately difficult for third-grade pupils, because it shows a reliable decrease in difficulty across elementary and secondary grades, and because pretesting on 15 classmates of the students in the present study showed a near-ceiling performance on a disjunctive problem (the next easiest rule).

\section{METHOD}

\section{Subjects}

Fifteen third-graders were randomly selected from the 49 third-graders in three homerooms of the Lamplighter School (a private school in Dallas serving children in nursery school through fourth grade). The experimenter was blind as to the homerooms of the children; 5 of the children tested were from each of the three third-grade homerooms.

\section{Design and Procedure}

In the fall of 1980,50 Texas Instruments $99 / 4$ home computers with LOGO software were placed in the Lamplighter School. Eleven of the computers were located in the third-grade area. In all three third-grade homerooms, the students were given the same LOGO instructions; however, in two homerooms the students had $.5 \mathrm{~h}$ of individual computer time per week (the .5 - $\mathrm{h}$ group), and in the third homeroom the students had $1 \mathrm{~h}$ of individual computer time per week (the 1 -h group). It is important to the design of the study to note that children spent only $1 \mathrm{~h} /$ day in their homerooms, that homeroom assignment was random, that the third grade was arranged on a partially open-classroom plan with a shared commons, and that the children spent, outside their homeroom classes, the remainder of the school day studying French, science, art, music, botany, drama, physical education, social sciences, language arts, and mathematics (these last two were ability tracked) under the direction of different members of the Lamplighter staff. Thus, except for the $1 \mathrm{~h}$ spent in homeroom and the extra individual computer time, there were no systematic differences between the children who had the extra individual computer time and the children who did not. Homeroom class time was used for LOGO instruction, for collecting homework, to hand out parental permission slips and information sheets, to work on Lamplighter Layers (a poultry-products corporation run by the students), to give evaluative exams, and to conduct the "administrivia" associated with grade-school teaching. Outside homeroom, all 49 third graders had equal access to the 11 computers on a firstcome basis during free time before school, during car pool, during lunch, and whenever they were unable to participate in physical education. Because the children were treated identically except for their scheduled individual computer time, any observed differences are most likely due to that computer work.

For rule-learning problems, a stimulus universe of four trinary variables was created. Slides of the 81 combinations of color (red, yellow, or green), shape (circle, square, or triangle), size (small, medium, or large), and number (one, two, or three) were made. Forty slides for each of three problems were arranged such that every run of 4 slides contained one exemplar of each truth-table category and every run of 10 slides contained two exemplars of each truth-table category. Otherwise, the slides were ordered randomly. The three rule-learning problems were used, all based on the conditional (if ... then) rule, but different in relevant attributes-one and square, red and triangle, and circle and yellow.

The subjects were tested individually. The rule-learning task was presented as a game in which the object was to determine the rule. The students were told that they would see slides that varied in color, size, shape, and number. They then saw 11 sample slides that they described completely. Next, they viewed the test slides, one at a time, indicated whether each slide obeyed or broke the unidentified rule, and received feedback on their answers. Prior to each problem, the students were told what the relevant attributes were and that they would be given "hints" during the game. The hints were merely reminders of the two relevant attributes and were given to the students at the beginning of each problem and after Slides 20,40,60, and 80. On each of the three problems, the students worked to a criterion of 12 consecutive correct judgments or until they had seen 100 slides.

Throughout the entire school year, the teachers were blind to the type of assessments used. Rule-learning testing was performed in the last 2 weeks of the school year.

\section{RESULTS AND DISCUSSION}

The 1-h-group children made significantly fewer errors than the .5 -h-group children; the mean numbers of errors were, respectively, 14.2 and $24.5[\mathrm{~F}(1,13)=5.14$, $\mathrm{p}<.05, \mathrm{MSe}=206.5]$. A close examination of the results shows that they cannot be attributed to one or two extreme scores. The differences in the two groups are quite striking; only 4 of the 10.5 -h-group students did better than the worst of the 1-h-group children. The 1-h-group students solved all except 2 of the 15 problems they attempted, but the .5 -h-group students failed to solve 10 of the 30 problems they tried.

A similar advantage for the 1-h students was displayed on the number of trials to criterion, although the difference was not statistically significant because of the large number of nonsolvers in the .5 -h group (as in the Bourne \& O'Banion study, scores of 100 were used for analysis of trials to criterion on unsolved problems); the means were 49.93 and $64.83[\mathrm{~F}(1,13)=3.83, \mathrm{p}=.07$, $\mathrm{MSe}=818.04]$. On neither the number of errors to criterion nor the number of trials to criterion was the effects of problem order or the interaction of problem order with computer time statistically significant (all Fs $<1$ ).

The superiority on rule learning displayed by the children with the extra computer time is consistent with the results of case studies. Unlike many studies on computer training that test a skill students have drilled with tedious CAI practice, the present study demonstrates, following computer work, an improvement in a more general measure of thinking. These results raise several important questions beyond that of replicability. Is it the case that the superior performance of the children with the extra computer time was due specifically to LOGO, or could similar results be obtained with other structured languages (e.g., PASCAL) or even with a nonstructured language (e.g., BASIC)? Does the superiority 
in rule learning shown by the 1-h-group children represent only a specific gain in classification of stimuli into conceptual or perceptual categories, or is it indicative of a broader, general problem-solving schema learned through working with LOGO? What additional gains might be achieved by students with even more work in LOGO? More practically, how might curricula be designed to take advantage of these potential gains? Unfortunately, it will soon become impossible to answer these questions because microcomputers are becoming so ubiquitous that it will be impossible to find students who have not had computer experience.

\section{REFERENCE NOTES}

1. Weir, S. LOGO as an information prosthetic for the handicapped (Working Paper 9). Camoridge: M.I.T., Division for Study and Research in Education, May 1981.

2. Watt, D., Papert, S., diSessa, A., \& Weir, S. Final report of the Brookline LOGO project Part II: Project summary and data analysis (LOGO Memo No. 53). Cambridge, Mass: M.I.T., Artificial Intelligence Lab, September, 1979.

\section{REFERENCES}

Bourne, L. E. Knowing and using concepts. Psychological Review, 1970, 77, 546-576.

Bourne, L. E., \& O'BAnion, K. Conceptual rule learning and chronological age. Developmental Psychology, 1971, 5, 525-534.

Kolata, G. How can computers get common sense? Science, 1982, 217, 1237-1238.

LAWLER, R. W. The progressive construction of mind. Cognitive Science, 1981, 5, 1-30.

PaPe rT, S. Mindstorms. New York: Basic Books, 1980.

Statz, J. A. The development of computer programming concepts and problem solving abilities among ten-year-olds learning LOGO. Unpublished doctoral dissertation, Syracuse University, 1973.

(Received for publication March 7, 1973.) 